\title{
Pesquisas de professores sobre práticas educativas com os laptops UCA na Escola Pública
}

\author{
Maria Eduarda L. Menezes ${ }^{1}$, Susana E. Kruger-Dissenha ${ }^{2}$, Maria Elizabeth B. de \\ Almeida ${ }^{3}$
}

1, 2, 3 Programa de Pós Graduação em Educação: Currículo

Pontifícia Universidade Católica de São Paulo (PUC-SP)

Caixa Postal 2419 - 05014-901- São Paulo - SP - Brazil

dudalima3@gmail.com, sekruger@uol.com.br, bbalmeida@uol.com.br

\begin{abstract}
This article presents and analyzes seven researches of teachers at a public school with laptops $U C A$, as part of a larger $C N P q$ research developed at PUC-SP. The teachers participated of activities and conducted research, reported their experiences in forms of activities and "reflective memorials" and a blog; in the end, they produced a report with the main results. Three questionnaires and two focus groups also contributed to the collection of data on the practices carried out and the reflections on these. The article culminates with the presentation of some of the main results and reflections on the research process and practices conducted in the school, and indicate some possibilities for other initiatives.
\end{abstract}

Resumo. Este artigo apresenta e analisa sete pesquisas de professores de uma escola pública sobre o uso do laptop UCA, enquanto parte de uma pesquisa CNPq desenvolvida na PUC-SP. Os professores das escolas participaram de atividades formativas e realizaram pesquisas, relatando suas experiências em formulários de atividades, memoriais reflexivos e alimentaram blogs; ao final, elaboraram um relatório com os principais resultados. Três grupos focais $e$ dois questionários também contribuíram para a coleta de dados sobre a formação, as práticas, as reflexões sobre estas e os resultados em sala de aula. São apresentados os principais resultados e reflexões sobre estes pontos, indicando possibilidades para iniciativas semelhantes. 


\section{Introdução}

O presente artigo reporta-se ao Projeto CNPq O currículo do século XXI: a integração das TIC ao currículo - inovação, conhecimento científico e aprendizagem, desenvolvido no Programa de Pós-Graduação em Educação: Currículo, da Pontifícia Universidade Católica de São Paulo, PUC-SP, coordenado pela Profa. Dra. Maria Elizabeth Bianconcini de Almeida. O mesmo contou também com a participação da Universidade Federal de Goiás - UFG e da Universidade Federal de Tocantins - UFT. O lócus da investigação foi distribuído em sete escolas municipais e estaduais de ensino fundamental, sendo três em São Paulo, duas em Goiás e duas no Tocantins. O objetivo principal consistiu em identificar as contribuições e dificuldades das ações de formação e das práticas realizadas nas escolas participantes do Projeto UCA, as mudanças desenvolvidas no currículo e nas práticas educativas, os indícios evidenciados de inovação educativa, bem como desenvolver um processo de intervenção contextualizado que possa impulsionar o uso do laptop de modo que este traga contribuições significativas ao desenvolvimento do currículo (ALMEIDA; BARRETO; JESUS, 2012).

Como parte desta pesquisa maior, foi prevista a realização de pesquisas por professores destas escolas UCA; portanto, de 2011 a 2013 foram submetidos projetos de pesquisa às universidades locais, que realizaram uma avaliação prévia e então os submeteram ao CNPq. Os projetos aprovados pelo $\mathrm{CNPq}$ foram contemplados com bolsas de auxílio a pesquisa que versava sobre as práticas com os laptops UCA em suas salas de aula. Outro projeto relacionado a esta pesquisa é o Pós-doutorado PNPD A sala de aula no século XXI: Inovação e Criticidade (Edital 001/2010 MEC/CAPES e MCT/CNPq/FINEP) (ALMEIDA, 2010, p. 03), do qual faz parte a pesquisa $A$ apropriação tecnológica e pedagógica das TICs pelos sujeitos das escolas participantes do Programa UCA: três estudos de caso (KRUGER-DISSENHA, 2012).

O presente artigo inicia com uma introdução ao percurso do Projeto UCA no Brasil e em seguida à pesquisa $\mathrm{CNPq}$ no qual se inserem os projetos dos professores. Em seguida, são descritos os sete projetos dos professores e seus principais resultados em sala de aula de uma escola municipal localizada no interior do Estado de São Paulo. $\mathrm{O}$ artigo continua apresentando alguns resultados encontrados nos grupos focais a respeito destes projetos, analisando a perspectiva dos professores participantes sobre o processo empreendido. Na última seção são apresentadas análises sobre os projetos e as perspectivas dos professores, culminando em indicações para a formação e a continuidade de pesquisas realizadas em escolas por professores.

\section{O contexto: o Projeto UCA e a pesquisa CNPq}

O Projeto Um Computador por Aluno, entendido como uma política pública brasileira de inclusão digital e social coordenada pelo MEC/SEB (Ministério da Educação/Secretaria da Educação), foi inspirado no Projeto One Laptop per Child $(O L P C)$, do MidiaLab do MIT (Laboratório de Mídias, Instituto de Tecnologia de Massachussets). O projeto visa fomentar a "qualidade da educação pública do Brasil pretendendo disponibilizar um computador para cada aluno de escola básica", utilizando softwares livres (ALMEIDA, 2009, p. 86).

Dentre os impactos ou facilitações do uso de distintos dispositivos digitais de informação e comunicação, entre os quais os laptop nas escolas, Almeida (2009) elenca 
a mobilidade (uso em diferentes ambientes inclusive fora da sala de aula ou da escola), a ruptura com as restrições de acesso (tempo de uso e espaço físico) ao computador no laboratório, assim como: a estrutura de armazenamento de dados faz uso da internet e do servidor que deverá estar disponível na escola, o que poderá impactar ou facilitar o acesso e a manipulação de recursos para desenvolver atividades colaborativas, compartilhar conhecimento com o mundo exterior e trazer a comunidade para dentro da escola (ALMEIDA, 2009 p. 86).

O Programa iniciou em 2007 com um Projeto Pré-piloto em cinco escolas públicas em diferentes estados brasileiros, sob coordenação da PUC-SP em parceria com outras universidades (UFG e UFT). O Projeto Piloto começou em 2010, em aproximadamente 300 (trezentas) escolas públicas brasileiras de redes estaduais e municipais, distribuídas entre escolas urbanas e rurais, além de 6 (seis) municípios de pequeno porte em que todas as escolas receberam os laptops, incluindo não apenas a distribuição de laptops com conexão a internet para alunos e professores, mas também a formação dos professores e gestores das respectivas escolas. Atualmente, ainda em paralelo com o Projeto UCA (Piloto), está sendo realizado o Programa UCA PROUCA, em forma de apoio do governo às prefeituras para que adquiram o laptop educacional e assim estimulem formas inovadoras e criativas de ensino e aprendizagem nas escolas, visando a inclusão digital e social de alunos e de seus familiares, de professores e outros profissionais das escolas. A Lei 12.715 de 17/09/2012 regulamenta os subsídios para a continuidade do Programa até 31/12/2015.

A pesquisa CNPq $O$ currículo do século XXI: a integração das TIC ao currículo - inovação, conhecimento científico e aprendizagem foi realizada entre 2011 e 2013 tendo como foco geral a integração das TDIC ao currículo das escolas que participam do Projeto UCA na Formação Brasil ministrada pela PUC-SP. Participaram principalmente os professores e os gestores destas escolas, e em alguns momentos também alunos e seus pais ou responsáveis. O acompanhamento e a formação ocorreram inicialmente no ambiente virtual E-Proinfo, com apoio em encontros presenciais entre todas as escolas $\mathrm{e}$ as equipes de pesquisadores, vídeo ou audioconferências via Skype, visitas às escolas, e-mail e contatos telefônicos.

O estudo teve três etapas: (1) diagnóstico, para identificação das mudanças nas práticas pedagógicas durante a Formação Brasil, as influências no currículo e as necessidades emergentes de formação para o uso do laptop nas escolas; (2) intervenção: formação contextualizada nas escolas, levando em consideração suas necessidades específicas; buscando o compartilhamento de experiências e a reflexão sobre a prática; (3) análise: processo reflexivo diante dos dados coletados durante o desenvolvimento da pesquisa e auto-avaliação da formação, das intervenções e das práticas realizadas.

A pesquisa teve o propósito de desenvolver o processo educativo baseado nas principais características da sociedade do século XXI, com o uso da tecnologia móvel conectada, o desenvolvimento de projetos e a flexibilidade de aprendizagem em relação ao tempo e espaço. Também se buscou com este estudo, uma forma sustentável de dar continuidade ao Projeto UCA nas escolas participantes da Fase II do projeto.

Neste texto as análises estão delimitadas aos projetos desenvolvidos em uma escola municipal do interior de São Paulo, conforme apresentado a seguir. 


\section{Os projetos desenvolvidos}

No Centro de Educação Municipal Neyde Tonanni Marão, na cidade de Votuporanga, foram realizados sete projetos por professoras bolsitas ${ }^{1}$ da pesquisa financiada pelo $\mathrm{CNPq}$, com apoio da equipe de pesquisadoras(es) da PUC-SP ${ }^{2}$. Os mesmos tiveram duração de quatro meses, entre o primeiro semestre de 2012 e o primeiro semestre de 2013, alcançando diferentes anos do Ensino Fundamental I. De forma geral, os projetos tinham caráter interdisciplinar e a tecnologia como base, mais especificamente as ferramentas do laptop educacional UCA e os recursos de pesquisa da Internet.

Durante este processo, os professores sistematizaram o planejamento, a prática e os resultados obtidos dos projetos em dois instrumentos: o memorial reflexivo e o formulário de registro das atividades de formação; ao final, entregaram um relatório geral complementado por fotos e depoimentos dos alunos. No blog de cada professor, também foi registrado o desenvolvimento dos projetos com fotografias, vídeos e trechos de depoimentos. A seguir, segue uma síntese de cada projeto.

O projeto "Diário digital" visou incentivar e desenvolver a leitura e a escrita com o uso do laptop durante a produção de um diário, no editor de texto, em que os alunos descreviam os fatos vivenciados no dia anterior. $\mathrm{O}$ projeto foi realizado com alunos da $4^{\mathrm{a}}$ série e envolvia Língua Portuguesa, História e Geografia. Os principais resultados foram uma maior facilidade de digitação e de descrição dos fatos considerados mais importantes para os alunos, em que se expressavam com autonomia e segurança. Além do mais, se mostraram independentes e responsáveis nas ações de carregar e guardar os laptops sozinhos. Este projeto aponta para a criação de narrativas digitais e indicações para a construção do web currículo (ALMEIDA, 2010b), que visa a integração da tecnologia e das mídias digitais aos processos de ensino e aprendizagem.

O projeto "Tecnologia e a sustentabilidade: convivendo com a reciclagem" foi desenvolvido com alunos do $3^{\circ}$ ano do Ensino Fundamental e tinha a convergência de Língua Portuguesa, Ciências, Geografia e Artes, visando ampliar o conhecimento e a consciência dos problemas do meio ambiente e da importância da reciclagem de lixo e da conservação dos recursos naturais. Foram utilizados os recursos audiovisuais do laptop para fotos e vídeos, bem como o editor de texto para registro. A classe realizou pesquisas sobre o meio ambiente e os problemas que o lixo traz à natureza, em uma visita numa estação de reciclagem de lixo próxima à escola. Os depoimentos coletados pela professora pesquisadora permitem inferir que os conhecimentos influenciaram, em certo grau, na mudança de cultura de reciclagem de lixo realizada nas casas dos alunos. O projeto buscou o desenvolvimento da responsabilidade e da cidadania dos alunos

\footnotetext{
${ }^{1}$ As professoras bolsistas foram: Crislaine Aparecida Santos Ribeiro, Flávia Maria da Silva Vilela, Sara Luciene da Silva Garcia, Elaine Momesso de Queiroz, Adriana Flavia de Martins e Lourenço (2 projetos), e Myriam Daniele Prudente Teixeira Nunes. As autoras agradecem imensamente sua participação na pesquisa, bem como à diretora Maria Vanilda Dalto, o atual coordenador pedagógico Aldo Cardenas Alonso pelo apoio constante ao Projeto UCA, e a coordenadora anterior Jackeline Savazi. Cabe mencionar também Suellen de Souza Lopes e Wesley Fernandes, que também apoiaram os(as) professores(as) da escola com seus conhecimentos tecnológicos. Agradecemos também aos demais professores da escola, que mesmo sem participar do Projeto CNPq participaram ativamente das formações, das ações pontuais da pesquisa e fizeram uso do laptop UCA em suas aulas.

2 Os(as) professores formadores/pesquisadores(as) da PUC-SP, que atuaram em diferentes momentos, foram: Odete Sidericoudes, Flaviana Santos Silva, Thiago Rodrigues Schulze, Sueli Mainine, Maria Célia Pimentel, Maria Eduarda de Lima Menezes e Susana Ester Kruger Dissenha.
} 
durante suas etapas e explorou a mobilidade do laptop em outro espaço além da sala de aula, propiciando um web currículo experienciado.

O projeto "Fazendo arte com o UCA" foi criado para os alunos da $3^{\circ}$ série e envolveu Artes, Língua Portuguesa, História, Sociedade e Cultura e Pluralidade Cultural,visando desenvolver a sensibilidade e a criatividade dos alunos por meio da Arte e conhecer com mais profundidade o trabalho do artista Romero Britto. Os alunos desenvolveram novas habilidades em ferramentas de apresentação, de edição de imagem e textos do laptop (KWord, KPresenter e Tux Paint) e realizaram pesquisas sobre o artista e as suas obras, criaram textos, imagens, apresentações e uma releitura de uma obra que mais se identificaram. No que tange ao currículo, o projeto buscou trabalhar o tema com diversas linguagens e proporcionou um estudo mais aprofundado das Artes, assim como o desenvolvimento da expressão artística dos alunos.

O projeto "Integração entre alfabetização e tecnologia" foi realizado com alunos da $1^{\text {a }}$ série e envolveu Língua Portuguesa, Matemática e Artes. Utilizando os jogos e demais recursos disponíveis no laptop, o projeto apoiou a alfabetização por meio da escrita e da representação numérica, além de trazer um conhecimento básico de informática aos alunos no uso do Tux Paint, KWord, jogos educacionais e câmera do laptop. Os alunos aprenderam o alfabeto com a construção de palavras e os números com uso de imagens e jogos. Destacou-se a alfabetização de um aluno com deficiências múltiplas que, segundo a professora, conseguiu aprender a escrever por meio do laptop, cujos recursos de digitação eram mais acessíveis tendo em vista suas limitações motoras. Este projeto expandiu o processo de alfabetização somente com a lousa e o livro impresso e utilizou os recursos tecnológicos como um facilitador, além de explorar múltiplas linguagens.

O projeto "Etapas para criação de histórias em quadrinhos" envolveu alunos da $3^{\text {a }}$ série e utilizou princípios da Língua Portuguesa, História e Artes. Tinha o objetivo de os alunos conhecerem e criarem histórias em quadrinhos (HQ) e com isso, desenvolver a produção de textos e a criatividade, com o uso do processador de texto e do editor de imagem. Foi realizada uma pesquisa sobre HQ e a apropriação do tema, com elaboração de um gibi virtual e o registro do processo no editor de texto do laptop. Os alunos conheceram mais sobre o tema do $\mathrm{HQ}$ e exploraram suas variáveis, como a onomatopéia. O projeto foi realizado de acordo com o currículo estabelecido e portanto, não houve indícios de mudança no desenvolvimento do currículo.

O projeto "Notícia a qualquer hora: o uso do gênero jornal na escola" foi desenvolvido com alunos da $5^{\text {a }}$ série visando promover o interesse pela leitura e escrita de notícias com o uso do laptop. Com o projeto, os alunos tiveram mais facilidade para ler as reportagens e assistir os vídeos jornalísticos selecionados pela professora acessados pela internet no laptop. Os alunos também expressavam sua opinião sobre as notícias de forma autônoma e crítica. Ao final, expuseram no pátio da escola um painel com as notícias lidas ao longo do projeto. $\mathrm{O}$ trabalho realizado com os alunos propiciou maior expressão verbal e expandiu hábito da leitura diária de notícias e a professora tende a planejar suas aulas antecipadamente.

O projeto "A Arte no contexto da inclusão digital" foi desenvolvido para os alunos da $4^{\mathrm{a}}$ série e envolveu Português e Artes para trazer o conhecimento e a vivência de diferentes saberes artísticos com o apoio do laptop, além de criar, apreciar e registrar as produções artísticas. Os alunos conheceram algumas características artísticas e 
desenvolveram sua criatividade com colagem de papéis e massa de modelar e potencializaram o conhecimento com pesquisas na internet e uso de recursos audiovisuais. Construíram habilidade para manusear o laptop, fizeram releituras de obras famosas e aprenderam diversas técnicas artísticas.

\section{Algumas perspectivas sobre práticas pedagógicas, pesquisas e seus resultados}

Durante o desenvolvimento da pesquisa CNPq, os pesquisadores realizaram uma coleta sistemática dos dados em cada escola participante, utilizando-se de diversos instrumentos, como a análise documental, questionários, entrevistas, grupo focal, dentre outros. Este artigo foi baseado nos dados obtidos em alguns grupos focais (grupo selecionado para discutir um determinado tema ou assunto). De acordo com Gatti (2005), nesta técnica o pesquisador tem interesse não somente em como as pessoas pensam e se expressam, mas também como pensam e por que pensam.

$\mathrm{Na}$ pesquisa $\mathrm{CNPq}$, os grupos focais foram realizados com alunos e professores em duas etapas, em 2011 e em 2013, com o mesmo roteiro de questões. O objetivo dos grupos focais foi identificar as vantagens e os desafios em relação ao uso do laptop nas atividades em sala de aula e em outros espaços.

Os alunos do grupo focal realizado em 2013 ressaltaram que aprenderam muito com o laptop e que seu uso havia trazido significativas mudanças em seu aprendizado. Também demonstraram ampla satisfação em realizar pesquisas sobre temas diversos, relacionados com o aprendizado em sala de aula ou assuntos que lhes causam curiosidade, conforme mostram os extratos de dados a seguir:

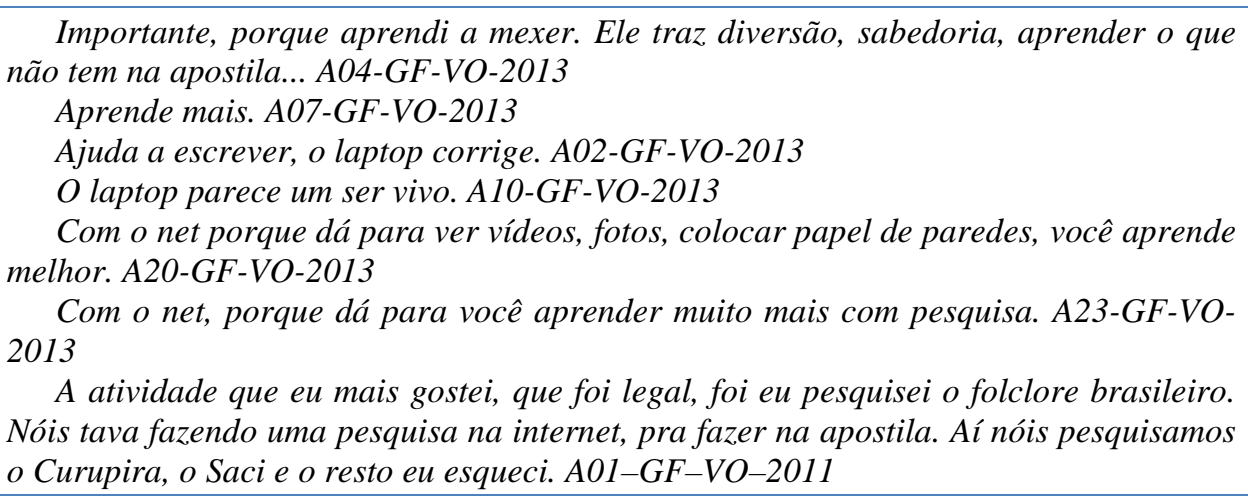

Segundo uma professora, a pesquisa, isto é, a busca de informações em distintas fontes, já faz parte do cotidiano dos alunos e professores, e além da motivação para realizar esta atividade, eles também ensinam aos próprios professores:

Eles gostam dessa prática, tem essa curiosidade, porque eles são muito curiosos, “ah, tia, eu vi isso daqui num desenho, quero saber como funciona, o que tem?” Eles mesmos vão pesquisar, agora quero ver isso, eles já se instigam a procurar saber, a querer. Tanto a gente ensina para eles procurar como eles ensinam para a gente. Suellen - P08-GFM-VO-2013

Sandholtz, Ringstaff e Dwyer (1997) realizaram um estudo em que identificaram e sistematizaram cinco estágios de apropriação das tecnologias: 
Exposição ou entrada: é o contato inicial com as tecnologias e de sua aprendizagem essencial.

Adoção: uso de recursos básicos, como o processador de texto, de forma instrucionista.

Adaptação: início do uso das tecnologias nas atividades tradicionais e busca de uma ampliação da produtividade dos alunos.

Apropriação: maior exploração do potencial das tecnologias e indícios de mudanças nas práticas pedagógicas.

Inovação: as tecnologias são utilizadas em novos contextos de ensino e provocam diferente experiências de aprendizagem para os alunos.

$\mathrm{Na}$ escola investigada, percebemos que os professores estão no estágio da adaptação, pois há um uso considerável do laptop durante as aulas e a busca por atividades que propiciem maior participação e produção dos alunos. No grupo focal, os professores refletiram sobre seu processo de apropriação, que começou com $o$ conhecimento do sistema operacional Linux no qual eles não eram habituados, e seu aprendizado foi estimulado e orientado inclusive pelos próprios alunos:

De início, o que me apavorou na formação foi a questão assim... passar tudo isso para os alunos, porque eu não tinha essa autonomia, e ainda sem contar que quando a gente começou a ter formação, era um outro programa. [...] eu sabia mexer no Windows, e, de repente, veio o Linux, então, assustou, assustou de início. Depois, passar por toda aquela formação que a gente teve para os alunos. Eu falei: "gente, eu não vou conseguir”. Eu que, às vezes, a gente, eu, acabo passando essa minha... eu não vou conseguir para os alunos, que os alunos também não vão. Mas o que eu percebi foi diferente, eles pegam com uma facilidade, eu via aluno me ensinando. Quando a gente passou o laptop pra eles, o aluno que me ensinou a colocar a tela, a mudar a foto, o aluno que me ensinou a desligar o som, sabe?! [...] P01-GFM-VO-2013

Uma professora, que se afastou da escola por um ano, relatou que percebeu diferenças na apropriação tecnológica entre o primeiro momento de uso dos laptops pelos professores, no início do processo de formação na escola, e algum tempo depois. A professora também registra uma forma de trabalho, que vai além da busca de informações em distintas fontes com as crianças coletando dados por meio de entrevistas, fornecendo indícios de um trabalho de produção dos alunos.

[...] Por exemplo, ano passado, eu não usei. Não estava aqui, estava em outra escola, não participei. Esse ano quando eu cheguei, fiz meu projeto [de pesquisa CNPq] para trabalhar com vocês. Muita coisa que eu coloquei no projeto, que eu achei que ia ensinar para as crianças; quando fui trabalhar com eles, eles acabaram me ensinando, entendeu? Eu me dei conta de que eles cresceram muito. Eu estava ainda com aquela ideia lá de 2011 que estava começando. Eles já sabem digitar, eles já sabem salvar, [...] eles já sabem fazer uma entrevista, entendeu? Muitas coisas que eu coloquei foi muito mais fácil de trabalhar. P04-GFM-VO-2013

O interesse dos professores em relação ao ato de pesquisar foi notado com intensidade durante os grupos focais. Além do recurso metodológico da entrevista, os professores também apresentaram interesse em outras técnicas, como demonstra o relato de uma das professoras participantes da pesquisa CNPq: 
Realizei todas as atividades propostas no curso de formação. Gostaria de conhecer práticas pedagógicas na formação.

Na formação gostaria de aprender sobre grupo focal e como fazer. Na sala gostaria de fazer um grupo focal com os alunos. (S, VO, Relatório final de pesquisa 2012).

Durante o processo de formação em pesquisa, é importante que o professor tenha claro a diferença entre a realização de pesquisa (aquela que parte da busca e envolve a produção dos alunos) e a prática reflexiva. Neste sentido, cabe lembrar Perrenoud (1999), que apresenta três diferenças entre a pesquisa e a prática reflexiva: (1) objeto da pesquisa: a pesquisa é mais ampla, pois "interessa-se por todos os fatos, processos e sistemas educativos e por todos os aspectos das práticas pedagógicas"; a prática reflexiva focaliza o cotidiano e o local de trabalho do professor - o "olhar sobre seu próprio trabalho e seu contexto imediato, no dia a dia"; (2) atitudes: a pesquisa descreve e explica para outros, e a prática reflexiva busca "compreender para regular, otimizar, ordenar, fazer evoluir uma prática particular a partir do seu interior"; (3) funções: Enquanto a pesquisa visa obter "saberes de caráter geral, duráveis, integráveis a teorias", a prática reflexiva busca "conscientizações e saberes da experiência úteis localmente"; (4) critérios de validação: na pesquisa, são requeridos método e controle, na prática reflexiva, é requerida a qualidade das regulações que ela permite operar e pela sua eficácia na identificação e resolução de problemas profissionais.

A apropriação tecnológica foi ressaltada como o primeiro passo para a utilização dos laptops na escola: "Primeiro, ela tem que conhecer o laptop, se ela não conhecer o laptop como ela vai ajudar alguém a usá-lo? Ela tem que ter essa informação e formação" (P05-GFT-VO-2013). Então, conhecendo os seus recursos, o planejamento e o uso pedagógico serão otimizados e possibilitarão maior integração das TDIC ao currículo:

Segundo momento, como passar para os alunos, dando a devida atenção a essa
ferramenta que chegou e vai te acompanhar para o resto da vida. De repente,
programas que poderiam te ajudar, qual a maior dificuldade dessa sala? Eles não
sabem ler? Eles não sabem escrever? O que você pode... Por exemplo, quando dou
alguma atividade da apostila, eles não conseguem visualizar. Eu acho que a
visualização é muito importante. A visualização fixa a compreensão. Quando você tem
a informação e a imagem, você junta os dois; eu acho que nesse sentido, se você tivesse
seu computador na sua mesa e pudesse consulta-lo o tempo todo, assim: "uma
montanha que tem 'essa' vegetação", mas "como é 'essa'vegetação”? Na hora que
você passa isso e mostra, fixa mais e você consegue imaginar e ver se o que você está
imaginando está certo ou errado. P05-GFT-VO-2013

O depoimento dessa professora indica que a apropriação tecnológica e pedagógica caminham juntas e as práticas de uso do laptop evoluem à medida que o professor domina as funcionalidades do laptop e identifica suas contribuições pedagógicas.

\section{Algumas reflexões e indicações}

Os sete projetos de pesquisa realizados pelos professores na escola foram trabalhados de forma interdisciplinar e com temas atuais, como reciclagem, sustentabilidade, notícias jornalísticas e a pluralidade cultural e artística. Cada projeto, de forma particular, fez uso de múltiplos recursos tecnológicos e de mídias digitais. 
Os projetos com o uso do laptop resultaram algumas mudanças positivas em relação à aprendizagem. Os alunos puderem expandir a capacidade de expressão por meio da criação de textos e desenhos, realizaram pesquisas sobre os temas estudados, desenvolveram novas habilidades, assim como responsabilidade, criatividade e autonomia. O laptop ainda proporcionou sua inclusão digital, já que a maioria não tem acesso ao computador e respectivos recursos devido às suas condições econômicas desfavoráveis.

Por meio da realização dos projetos, percebeu-se a parceria e a colaboração entre alunos e professores, principalmente no uso do sistema operacional Linux, que era desconhecido por todos da escola. Em relação aos professores, suas aulas são cada vez mais planejadas para incluir $\mathrm{m}$ uso do laptop e criaram o hábito de registrar as atividades desenvolvidas no projeto, por meio de texto, vídeos e fotografias reunidos no blog pessoal de cada professor.

A partir da formação e por meio do desenvolvimento dos projetos de pesquisa, pode ser constatada uma maior integração da tecnologia na prática pedagógica dos professores. A apropriação das tecnologias e sua integração às atividades pedagógicas ocorreram de modo gradativo e assim foi possível identificar que se encontram no estágio de adaptação (SANDHOLTZ, RINGSTAFF, DWYER, 1997).

Para além disso, a pesquisa $\mathrm{CNPq}$ provocou maior interesse dos professores pelo ato de pesquisar e até em desenvolver algumas metodologias com os alunos em sala de aula, como entrevistas. Porém, ainda é necessário que a formação em pesquisa seja incentivada, para que ocorra uma maior consciência sobre elementos comuns e diferenciadores entre a pesquisa e a prática reflexiva (PERRENOUD, 1999).

Tanto a pesquisa quanto a prática reflexiva são importantes no contexto escolar. Quando pensadas complementarmente, podem auxiliar na compreensão das práticas, integrar atividades de pesquisa e prática entre pesquisadores (da "academia") e da escola, e gerar resultados que permitam conhecer melhor o contexto estudado. $\mathrm{O}$ conhecimento de metodologias e técnicas de pesquisa é almejado também pelos professores do ensino básico.

Assim, entre as possíveis indicações para a continuidade de pesquisas realizadas em escolas por professores, ressaltam-se a pertinência da formação em várias áreas, como práticas educativas (sempre de cunho reflexivo, como feito na pesquisa aqui relatada), tecnologias educacionais (incluindo o conhecimento básico e instrumental de sistemas operacionais ou softwares que sejam desconhecidos pelos professores), e em pesquisa, enquanto recurso para aprofundar as reflexões sobre as práticas e integrar ações em projetos realizados conjuntamente entre professores da educação básica e de ensino superior/programas de pós-graduação.

\section{Referências}

Almeida, M. E. B. (2009) "Gestão de tecnologias, mídias e recursos na escola: o compartilhar de significados”. In: Aberto, Brasília, v. 22, n. 79, p. 75-89. Disponível em: http://emaberto.inep.gov.br/index.php/emaberto/article/view/1435/1170. Acesso em: 15/06/2013.

Almeida, M. E. B. (2010a) Projeto CNPq “O currículo do século XXI: a integração das TIC ao currículo - inovação, conhecimento científico e aprendizagem”. São Paulo. 
Almeida, M. E. B. (2010b) "Integração de currículo e tecnologias: a emergência de web currículo". Anais do XV Endipe - Encontro Nacional de Didática e Prática de Ensino. Belo Horizonte: UFMG.

Almeida, M. E. B.; Barreto, G. O.; Jesus, V. G. S. (2012) "O currículo da escola do século XXI: a integração das TIC ao currículo: inovação, conhecimento científico e aprendizagem". In: FERRENTINI, F. S; ELIA, M. F.(orgs.). Projeto um computador por aluno: pesquisas e perspectivas- Rio de Janeiro: NCE/UFRJ, 2012. pp. 259 270. Disponível em: http://www.nce.ufrj.br/ginape/livro-prouca. Acesso em 08/10/2013.

Gatti, B. A. (2005) "Grupo focal na pesquisa em ciências sociais e humanas". Brasília: Líber Livro.

Kruger-Dissenha, S. E. (2012). "A apropriação tecnológica e pedagógica das TICs pelos sujeitos das escolas participantes do Programa UCA: três estudos de caso". Projeto de Pós Doutorado em Andamento na PUC-SP, Programa de Pós-graduação em Educação: Currículo. Aprovado no Edital PNPD - CAPES.

Perrenoud, P. (1999) "Formar professores em contextos sociais em mudança: Prática reflexiva e participação crítica". Trad. Denice Barbara Catani. Apresentado na XXII Reunião Anual da ANPEd, Caxambu. Revista Brasileira de Educação, n. 12, Set/Out/Nov/Dez/1999, p. 05-21. Disponível em: http://www.anped.org.br/rbe/rbedigital/RBDE12/RBDE12_03_PHILIPPE_PERREN OUD.pdf. Acesso em 10/05/2013.

Sandholtz, J. H.; Ringstaff, C.; Dwyer, D. C. (1997). "Ensinando com tecnologia: criando salas de aula centradas nos alunos". Porto Alegre: Artes Medicas. 